\title{
Mania/hipomania induzida por aripiprazol
}

\author{
Manic/hypomanic symptoms induced by aripiprazole
}

\author{
Márcio Gerhardt Soeiro de Souzaํ, Carlos Henrique Rodrigues dos Santos¹, Ricardo Alberto Moreno ${ }^{1}$ \\ 1 Grupo de Estudos de Doenças Afetivas (Gruda) do Instituto de Psiquiatria do Hospital das Clínicas da Faculdade de Medicina da Universidade de São Paulo (IPq-HCFMUSP).
}

Recebido: 18/8/2009 - Aceito: 29/10/2009

\section{Resumo}

Aripiprazol é um antipsicótico atípico (AAt) frequentemente indicado para o tratamento agudo da mania, assim como para quadros mistos de transtorno bipolar (TB) tipo I e para o tratamento de manutenção do TB tipo I. A potencial ação antidepressiva dos AAts possibilita que medicamentos dessa classe aumentem as chances do aparecimento de mania em indivíduos suscetíveis. Com o objetivo de sumarizar evidência que possibilite a discussão técnica desse tópico, aqui relatamos três casos de pacientes com TB com mania induzida por aripiprazol. Pacientes tinham diagnósticos e comorbidades diferentes e estavam em regime terapêutico também diferente. Mania foi temporalmente associada à introdução de aripiprazol. Melhora considerável aconteceu após a retirada do fármaco. Sugerimos que o aripiprazol, por meio da sua ação antidepressiva, seja fator de risco para virada maníaca e hipomaníaca. Recomendamos o uso associado de estabilizador de humor com potencial antimaníaco para prevenir eventual inversão de fase. Sugere-se, ainda, a provável eficácia antidepressiva do aripiprazol.

Souza MGS, et al. / Rev Psiq Clín. 2010;37(4):175-7

Palavras-chave: Depressão bipolar, virada maníaca, aripiprazol, hipomania induzida.

\begin{abstract}
Aripiprazole is an atypical antipsychotic often used as monotherapy or as add-on therapy in patients with manic episodes, as well as for bipolar disorders. The antidepressive effect of the atypical antipsychotic medications raises the possibility that these drugs may increase the risk of mania in susceptible individuals. With the aim of providing further evidence on this subject, herein we reported three patients with bipolar disorder and mania induced by aripiprazole. Patients had different final diagnosis as well as different comorbidities. Their therapeutic regimen was different as well. Onset of manias was temporarily associated with aripiprazole use and important improvement happened after the discontinuation of this drug. We suggest that aripiprazole, due to its antidepressant properties, is a risk factor for mania and hypomania. Mood stabilizer is recommended in certain individuals using this drug, in order to prevent phase switch. We also suggest the antidepressant efficacy of aripiprazole.
\end{abstract}

Souza MGS, et al. / Rev Psiq Clín. 2010;37(4):175-7

Keywords: Bipolar disorder, bipolar depression, mania, aripiprazole, side effects.

\section{Introdução}

Os antipsicóticos atípicos (AAt) são amplamente prescritos para o tratamento de transtornos psicóticos, assim como para episódios maníacos (olanzapina, quetiapina, ziprazidona e aripiprazol) ou depressivos (olanzapina, quetiapina) em pacientes com transtorno bipolar (TB) ${ }^{1}$. Entre eles, aripiprazol é indicado para o tratamento agudo da mania, assim como para quadros mistos de TB tipo I e para o tratamento de manutenção do TB tipo $\mathrm{I}^{2}$. O aripiprazol é ainda aprovado para o tratamento adjuvante do TB tipo I com resposta insatisfatória a lítio ou ao valproato de sódio, assim como tratamento adjuvante de transtorno depressivo maior com resposta parcial ao tratamento antidepressivo3.

A potencial ação antidepressiva dos AAts possibilita que medicamentos dessa classe aumentem as chances do aparecimento de mania em indivíduos suscetíveis, conforme previamente revisado por Michalopoulou e Lykouras 4 . O mecanismo de ação do aripiprazol envolve o bloqueio de receptores de serotonina (5HT) tipo 2A, o agonismo parcial de receptores 5HT1A e de dopamina tipo 2. A liberação de dopamina em nível frontal pode induzir o aparecimendo de sintomas maníacos 5,6 .

Casos de mania/hipomania associados ao uso de olanzapina, quetiapina, risperidona e ziprazidona foram descritos ${ }^{4,6-9}$. Com o objetivo de sumarizar evidência que possibilite a discussão técnica desse tópico, aqui relatamos três casos de pacientes com TB que apresentaram síndrome maníaca ou hipomaníaca associada ao tratamento com o aripiprazol.

\section{Caso 1}

EK 41 anos, homem, economista, em tratamento psiquiátrico desde os 15 anos de idade, com diagnóstico firmado de TB tipo I associado a transtorno obsessivo-compulsivo e obesidade (IMC $29,14 \mathrm{~kg} / \mathrm{m}^{2}$ ). Apresenta história familiar de TB, assim como depressão em parentes de primeiro grau.

Após início de tratamento com aripiprazol para a fase depressiva, ao atingir a dose de $60 \mathrm{mg}$ (Figura 1), paciente apresentou inversão para quadro maníaco psicótico. Seu escore na Young Mania Rating Scale (YMRS) chegou a 36, com diminuição do tempo total de sono, hipersexualização, medo generalizado, ideias persecutórias e gastos excessivos. Seus sintomas obsessivo-compulsivos também pioraram.

$\mathrm{O}$ paciente perdeu $30 \mathrm{~kg}$ em quatro meses. Foi internado, houve descontinuação gradual do aripiprazol e foi iniciado tratamento com eletrocolvulsoterapia (ECT). A remissão dos sintomas afetivos e psicóticos foi obtida após 14 aplicações bilaterais, persistindo em regime de uma aplicação mensal para manutenção.

\section{Caso 2}

MGT, 30 anos, homem, contador. Apresenta TB tipo II desde os 28 anos. Apresenta ainda tiques orofaciais e de tronco, assim como história familiar positiva para depressão e ansiedade (parentes de primeiro grau).

Foi submetido a diversos ensaios antidepressivos sem melhora da depressão, evoluindo com oscilações frequentes do humor. 


\begin{tabular}{|c|c|c|c|}
\hline Tratame & Depressão & Eutimia & Mania \\
\hline Ris $9+0 x c 900$ & & & \\
\hline Ris $6+0 x c 1200$ & & & \\
\hline Ris $3+0 x c 1200$ & & & \\
\hline Ris $6+0 \times c 600$ & & & \\
\hline Ris $6+$ Ari 60 & & & \\
\hline Oxc 1200 & & & \\
\hline Li 900 + Dul 60 & & & \\
\hline Li 1125 + Dul 60 & & & \\
\hline Li 1125 + Dul 60 & & & \\
\hline Li 1350 + Dul 60 & & & \\
\hline Li 1350 + Dul 60 & & & \\
\hline Li 900 & & & \\
\hline Li 900 + Bup 150 & & & \\
\hline Li $900+$ Ari 7,5 & & & \\
\hline Li $900+0$ lz 5 & & & \\
\hline
\end{tabular}

Figura 1. Afetivograma. Ris: risperidona; Oxc: oxcarbazepina; Ari: aripiprazole; Pim: pimozide; Li: lítio; Dul: duloxetina; Bup: bupropiona; Olz: olanzapina. Área preta: caso 1, área cinza-escuro caso 2, área cinza-claro caso 3.

Apresentava irritabilidade, anedonia, isolamento social, inversão do ciclo sono/vigília, atitude prostrada e com várias queixas somáticas, especialmente de dor.

Cerca de 20 dias após a introdução do aripiprazol, com titulação para $15 \mathrm{mg}$, apresentou virada para fase maníaca (YMRS $=29$ ), caracterizada por diminuição da necessidade de sono, sensação de bem-estar, aumento da libido, inquietação, irritabilidade, diminuição da concentração e hiperprodutividade. Apresentou ainda piora dos tiques. Não houve alteração laboratorial significativa. A remissão da fase maníaca ocorreu após a introdução de pimozida $1 \mathrm{mg}$ e suspensão do aripiprazol.

\section{Caso 3}

LTBF, 51 anos, médico, há 10 anos diagnosticado como TB tipo II. Apresenta ainda hepatite B cronificada e cardiopatia isquêmica. História familiar é positiva para depressão psicótica. Tabagista, cerca de 20 cigarros por dia.

Em função da história clínica de sintomas depressivos refratários ao tratamento adequado (Figura 1), aripiprazol 7,5 mg/dia foi associado à sua medicação de manutenção. Evoluiu com virada afetiva (YMRS = 26), relatando exaltação, bem-estar excessivo, hipersexualização, gastos excessivos e menor necessidade de sono. Apresentava ideias de grandiosidade e hiperprodutividade.

$\mathrm{O}$ aripiprazol foi substituído por olanzapina $5 \mathrm{mg}$ e o lítio foi ajustado. Evoluiu com remissão dos sintomas maníacos.

\section{Discussão}

Relatamos três casos com episódios maníacos provavelmente induzidos pelo aripiprazol. Pacientes apresentavam diagnósticos diferentes e eram tratados com esquemas medicamentosos também diversos. Isso impede a generalização do risco desse evento para a população geral e seria necessário um estudo em grande escala para se obterem dados mais consistentes.
A politerapia (aripiprazol associado a outros medicamentos) levanta a possibilidade de que o evento observado possa ter sido resultado de uma interação medicamentosa ou alterações no metabolismo das drogas, em vez de ter sido exclusivamente induzido pelo aripiprazol. Outra possibilidade a ser considerada é que os casos relatados já estivessem progredindo para mania antes da introdução do aripiprazol. Entretanto, dada a rapidez com a qual o quadro foi revertido com a suspensão da medicação, essa hipótese é pouco provável.

Quando nos deparamos com um evento medicamentoso adverso, é de importância: documentar claramente os sintomas prévios e sua duração; descartar a possibilidade de causa orgânica; descartar que o evento tenha sido causado por abuso de substâncias; analisar a relação da posologia, dose e ajustes medicamentosos recentes utilizados; descrever a remissão e sua duração.

Avaliando as possíveis causas do efeito adverso, vale ressaltar que nenhum dos casos esteve associado a abuso de drogas ou álcool. Os três pacientes encontravam-se em fase depressiva leve/ moderada no momento da introdução da medicação. No primeiro caso, a retirada gradual de $1.200 \mathrm{mg}$ de oxcarbamazepina coincidiu com o aumento do aripiprazol de 30 para $45 \mathrm{mg}$. Apesar de o anticonvulsivante reduzir os níveis de aripiprazol, isso poderia ser uma variável de confusão. No segundo caso, a virada para o quadro afetivo ocorreu com aumento do aripiprazol de $15 \mathrm{mg}$ para $30 \mathrm{mg}$. O uso de duloxetina concomitante poderia aumentar os níveis séricos de aripiprazol e ser considerado também como variável de confusão. No terceiro caso, a retirada da bupropiona coincidiu com a introdução de $7,5 \mathrm{mg}$ de aripiprazol. Bupropiona pode induzir o aumento dos níveis de aripiprazol. Pode-se ainda discutir que a ativação psicomotora e a acatisia são possíveis efeitos colaterais do aripiprazol, podendo ser erroneamente interpretados como sintomas maníacos. No entanto, nesses relatos, diagnosticou-se mania/hipomania com base em sintomas clínicos presentes nos critérios do DSM-IV e na pontuação YMRS, e não meramente decorrente da observação de sintomas unitários de ativação psicomotora ou acatisia.

A mania ou hipomania observada com o uso do aripiprazol foi manejada de formas diferentes. No primeiro caso, houve necessidade de ECT; no segundo caso, baixas doses de antipsicótico típico foram associadas; no terceiro caso, olanzapina foi associada e ajustou-se o lítio. A opção terapêutica nos casos relatados foi eficiente, mas cabe lembrar que o evento ocorreu com uso de doses baixas da medicação em dois dos casos.

Entre as hipóteses que buscam justificar a indução maníaca desencadeada após introdução de AAt, a mais contundente é que, quando estes são utilizados em doses menores, inicialmente promoveriam o bloqueio dos receptores 5-HT2A sem que tenham bloqueado os receptores $\mathrm{D} 2$; como consequência, haveria uma liberação de dopamina em nível frontal, levando à indução de sintomas maníacos ${ }^{10-12}$. $\mathrm{O}$ aripiprazol tem como característica particular a atuação como agonista parcial dos receptores dopaminérgicos, promovendo redução e aumento da neurotransmissão mediada pela dopamina nas áreas de hiper e hipoatividade dopaminégica, respectivamente, sem resultar no bloqueio completo dos receptores dopaminérgicos ${ }^{2}$. Por meio dessa atividade intrínseca, mantém a neurotransmissão mediada por dopamina em níveis de intensidade menores, porém eficazes ${ }^{8}$. Outra característica é sua grande afinidade pelos receptores D2 e D3 e sua moderada afinidade pelo D4 ${ }^{13-15}$. Vários estudos têm confirmado sua seletiva atividade antagônica e agônica que age dependendo de a atividade cerebral regional ser hiper ou hipodopaminérgica, respectivamente ${ }^{10}$.

A partir desses dados, podemos concluir que os antipsicóticos atípicos, incluindo o aripiprazol, por meio da sua ação antidepressiva, apresentariam potencial para indução de virada maníaca e hipomaníaca; sugere-se ainda a provável eficácia antidepressiva do aripiprazol, na medida em que representa uma importante promessa ao arsenal terapêutico no tratamento do transtorno bipolar com predominância depressiva, como adjuvante ou em monoterapia no tratamento das depressões unipolares resistentes. Necessitamos, para isso, de mais estudos clínicos para confirmar tal hipótese. 


\section{Referências}

1. Moreno RA, Moreno DH, Ratzke R. Diagnóstico, tratamento e prevenção da mania e da hipomania no transtorno bipolar. Rev Psiq Clín. 2004; (Sup 1):39-48.

2. Elkis H, Louzã MR. Novos antipsicóticos para o tratamento da esquizofrenia. Rev Psiq Clín. 2007;34(supl 2):193-7.

3. Homepage of the Food and Drug Administration. Disponível em: http:// www.fda.gov. Acessado em: 7 maio 2009.

4. Michalopoulou PG, Lykouras L. Manic/hypomanic symptoms induced by atypical antipsychotics: a review of the reported cases. Prog Neuropsychopharmacol Biol Psychiatry. 2006;30(4):549-64.

5. Stahl D, Sum CF, Lum SS, et al. Screening for depressive symptoms: validation of the center for epidemiologic studies depression scale (CES-D) in a multiethnic group of patients with diabetes in Singapore. Diabetes Care. 2008;31(6):1118-9.

6. Padala PR, Wengel SP, Petty F. Manic episode during treatment with aripiprazole. Am J Psychiatry. 2007;164(1):172-3.

7. Barnas ME, Hussain N, Petrides G. Treatment-emergent psychosis with aripiprazole. J Clin Psychiatry. 2005;66(10):1339.

8. Rachid F, Bertschy G, Bondolfi G, Aubry JM. Possible induction of mania or hypomania by atypical antipsychotics: an updated review of reported cases. J Clin Psychiatry. 2004;65(11):1537-45.

9. Aubry JM, Simon AE, Bertschy G. Possible induction of mania and hypomania by olanzapine or risperidone: a critical review of reported cases. J Clin Psychiatry. 2000;61(9):649-55.
10. Schmidt AW, Lebel LA, Howard HR Jr, Zorn SH. Ziprasidone: a novel antipsychotic agent with a unique human receptor binding profile. Eur J Pharmacol. 2001;425(3):197-201.

11. Rollema H, Lu Y, Schmidt AW, Sprouse JS, Zorn SH. 5-HT(1A) receptor activation contributes to ziprasidone-induced dopamine release in the rat prefrontal cortex. Biol Psychiatry. 2000;48(3):229-37.

12. Ichikawa J, Ishii H, Bonaccorso S, Fowler WL, O'Laughlin IA, Meltzer HY. 5-HT(2A) and $\mathrm{D}(2)$ receptor blockade increases cortical DA release via 5-HT(1A) receptor activation: a possible mechanism of atypical antipsychotic-induced cortical dopamine release. J Neurochem. 2001;76(5):1521-31.

13. Burris KD, Molski TF, Xu C, Ryan E, Tottori K, Kikuchi T, et al. Aripiprazole, a novel antipsychotic, is a high-affinity partial agonist at human dopamine D2 receptors. J Pharmacol Exp Ther. 2002;302:381-9.

14. Kikuchi T, Tottori K, Uwahodo Y, Hirose T, Miwa T, Oshiro Y, Morita S. 7-(4-[4-(2,3-Dichlorophenyl)-1-piperazinyl]butyloxy)-3,4-dihydro2(1H)-quinolinone (OPC-14597), a new putative antipsychotic drug with both presynaptic dopamine autoreceptor agonistic activity and postsynaptic D2 receptor antagonistic activity. J Pharmacol Exp Ther. 1995;274:329-36.

15. Lawler CP, Prioleau C, Lewis MM, Mak C, Jiang D, Schetz JA, et al. Interactions of the novel antipsychotic aripiprazole (OPC-14597) with dopamine and serotonin receptor subtypes. Neuropsychopharmacology. 1999;20:612-27. 